\title{
PEMBERIAN JUS BUAH PIR YALI (Pyrus bretschneideri) TERHADAP KADAR KOLESTEROL TOTAL PADA DARAH HEWAN COBA KELINCI (Oryotolagus cuniculus)
}

\author{
Hana Fatinah $^{1}$, Erlin Yustin Tatontos ${ }^{2}$, Lalu Srigede ${ }^{3}$ \\ ${ }^{1-3}$ Jurusan Analis Kesehatan, Poltekkes Kemenkes Mataram, Indonesia
}

\begin{tabular}{l}
\hline Article Info \\
Article history: \\
Received Jul $4^{\text {th }}, 2018$ \\
Revised Aug $2^{\text {th }}, 2018$ \\
Accepted Sept $18^{\text {th }}, 2018$ \\
\hline
\end{tabular}

Keyword:

Juice

Total cholesterol

Pear yali

\begin{abstract}
Cholesterol is a substance needed by the body. However, if there are a high number or beyond normal limits will lead to coronary heart disease (CHD) due to atherosclerosis. One factor that can lower cholesterol levels is to consume Yali pear (P. bretschneideri) which contain fiber and vitamin $C$. The aim of this study is an unknown effect of Yali pear fruit juice (P. bretschneideri) against total cholesterol levels in the blood of experimental animals rabbit $(O$. cuniculus). The study design is a pre-experiment. The treatment consisted of administration of a mixture of yellow eggs and sugar 90\% water for hypercholesterolemia, and provision of Yali pear fruit juice 1 time each day on 6 rabbits with a weight appropriate dose of the experimental animal's rabbits and data analysis presented descriptively. The results showed that Yali pear fruit juice can lower total cholesterol blood test animals rabbits so it can be concluded that there is the effect of Yali pear fruit juice on cholesterol levels in the blood of experimental animals total rabbit.
\end{abstract}

\begin{abstract}
ABSTRAK
Kolesterol adalah zat yang dibutuhkan oleh tubuh. Namun, jika terdapat dalam jumlah yang tinggi atau melebihi batas normal akan menyebabkan penyakit jantung koroner (PJK) akibat dari arterosklerosis. Salah satu faktor yang dapat menurunkan kadar kolesterol adalah mengonsumsi buah pir Yali (P. bretschneideri) yang mengandung serat dan vitamin $\mathrm{C}$. Tujuan penelitian ini adalah diketahui pengaruh pemberian jus buah Pir Yali (P. bretschneideri) terhadap kadar kolesterol total pada darah hewan coba kelinci (O. cuniculus). Rancangan penelitian ini bersifat pra-eksperiment. Perlakuan terdiri atas pemberian campuran kuning telur ayam ras dan air gula pasir $90 \%$ untuk hiperkolesterol, dan pemberian jus buah Pir Yali masing-masing 1 kali sehari pada 6 ekor kelinci dengan dosis sesuai berat badan hewan coba kelinci dan analisa data disajikan secara deskriptif. Hasil penelitian menunjukkan bahwa jus buah Pir Yali dapat menurunkan kadar kolesterol total darah hewan coba kelinci, sehingga dapat disimpulkan ada pengaruh pemberian jus buah Pir Yali terhadap kadar kolesterol total pada darah hewan coba kelinci. Saran pada peneliti selanjutnya apabila akan melakukan penelitian tentang pemberian buah Pir Yali terhadap kadar kolesterol total sebaiknya menggunakan ekstrak buah Pir Yali.
\end{abstract}

Kata kunci : Jus, Kolesterol Total, Pir Yali 


\section{Pendahuluan}

Kolesterol adalah komponen lemak darah yang dibutuhkan secara normal diproduksi sendiri dalam jumlah yang tepat, namun kolesterol juga dapat meningkat. kolesterol dalam jumlah tinggi menyebabkan hiperkolesterolemia (Vanessa, 2013). Hiperkolesterolemia merupakan suatu keadaan peningkatan kadar kolesterol total $=200 \mathrm{mg} / \mathrm{dl}$ dan mempunyai hubungan yang erat dengan keparahan aterosklerosis atau timbulnya lemak di saluran pembuluh darah yang menjadi salah satu faktor terjadinya penyakit jantung dan kardiovaskuler (Sulistyaningsih, 2015).

Di Indonesia angka kejadian PKV menunjukkan peningkatan dari tahun ke tahun. Pada Survei Kesehatan Rumah Tangga (SKRT) tahun 1986, PKV menjadi penyebab kematian nomor tiga untuk usia di atas 40 tahun dan kemudian menjadi nomor satu pada tahun 1995 untuk usiA 35-44 tahun (Kartika, 2016). Menurut WHO penyakit kardiovaskuler adalah penyebab nomor satu kematian secara global. Salah satu penyakit kardiovaskuler adalah Penyakit Jantung Koroner (PJK) yang merupakan ganguan jantung disebabkan akibat aterosklerosis (Glory, 2016). Aterosklerosis disebabkan oleh kadar kolesterol yang tinggi dalam darah.

Buah Pir Yali (Pyrus bretschneideri) adalah buah yang berasal dari daerah beriklim tropis di Eropa Barat, Asia dan Afrika Utara. Pohonnya berketinggian sedang, bisa mencapai 10-17 meter tapi sebagian spesies merupakan pohon yang pendek yang memiliki daun yang rimbun. Kandungan serat yang cukup tinggi dan Vitamin C (Asam askorbat) pada buah Pir Yali dapat menurunkan kadar kolesterol total karena sejalan dengan hasil penelitian (Zuhrawati 2014) membuktikan bahwa pemberian jus nanas yang mengandung tinggi serat dan Vitamin C (Asam askorbat) pada kelinci hiperkolesterolemia mampu menurunkan kolesterol total darah. Penelitian lain juga menunjukkan, satu buah apel yang di makan setiap hari dapat menurunkan kolesterol sebanyak 10\% (Lailiya, 2011).

Di kalangan ilmu kedokteran kelinci mempunyai jasa yang cukup besar karena sering menjadi alat percobaan atau riset (Widodo, 2017). Berdasarkan uraian tersebut peneliti tertarik untuk melakukan penelitian pengaruh pemberian jus buah Pir Yali (P. bretschneideri) terhadap penurunan kadar kolesterol total pada darah hewan coba kelinci (O. cuniculus).

\section{Metode Penelitian}

Penelitian ini telah dilaksanakan di Laboratorium Fakultas Kedokteran Universitas Mataram. Penelitian ini merupakan penelitian Pra-eksperimet dengan rancangan penelitian one group pretest-postest. Subjek pada penelitian ini adalah kelinci dengan berat $300-2500 \mathrm{~g}$, usia 3-12 bulan. variabel bebas dalam penelitian ini adalah Jus buah Pir Yali dengan dosis $8 \mathrm{ml} / \mathrm{kg}$ berat badan kelinci dan variable terikatnya adalah Kadar kolesterol total. Untuk mendapatkan gambaran secara jelas, jalannya penelitian ini adalah sebagai berikut.

Tahap pertama yaitu aklimatisasi hewan coba kelinci. Aklimatisasi hewan coba dilakukan selama 1 minggu dengan menggunakan air, makanan standar (kangkung, kol, wortel, rumput, nasi dan pakan ayam) dan kondisi lingkungan. menggunakan kelinci (O. cuniculus) dengan berat badan 300-2500 gram,usia 3-12 bulan, dengan kondisi sehat fisik, karena beberapa alasan yaitu mudah dipelihara dan dikembangbiakkan, mudah diambil darahnya dan fisiologisnya diperkirakan identik dengan manusia.

Tahap kedua yaitu pembuatan kondisi hiperkolesterolemia pada hewan coba kelinci. Pembuatan kondisi hiperkolesterolemia pada hewan coba kelinci dibuat dengan cara menginnjeksi kelinci dengan makanan kaya akan lemak yaitu campuran air gula pasir 90\% dan kuning telur ayam ras setiap 1 kali sehari selama 7 hari.

Tahap ketiga yaitu pemeriksaan kadar kolesterol total pada hewan coba kelinci. Kelinci diambil darahnya melalui telinga dengan menjepit telinga luar lalu darah diambil dengan menggunakan lancet yang ditusukkan pada bagian vena atau arteri central pada permukaan dorsal telinga. Sebelumnya, hewan coba dipuasakan terlebih dahulu selama $17 \mathrm{jam}$, air minum tetap diberikan dan pada pagi hari dilakukan pengukuran kadar kolesterol tortal kelinci dengan menggunakan Easy Touch GCU metode stik.

Tahap keempat yaitu pembuatan jus Pir Yali. Buah Pir Yali diblender tanpa penambahan aquadest kemudian jus ditimbang berdasarkan berat badan masing-masing hewan coba. Tahap kelima yaitu perlakuan terhadap hewan coba kelinci. Kelinci yang sudah hiperkolesterolemia diberi jus buah Pir Yali 1 kali sehari selama 10 hari sesuai berat badan hewan coba. 
Tahap keenam yaitu pengukuran kadar kolesterol total setelah pemberian jus buah Pir Yali. Kelinci yang sudah diberikan jus buah Pir Yali selama 10 hari ditimbang berat badannya kemudian dilakukan pengambilan darah kelinci dan dilakukan pengukuran kadar kolesterol tortal kelinci dengan menggunakan Easy Touch GCU metode stik. Data yang diperoleh dari hasil pemeriksaan kadarkolesterol total sebelum dan setelah perlakuan pada masing-masing unit eksperiment dilakukan dengan menggunakanan alisis data deskriptif.

\section{Hasil Penelitian}

Hasil penimbangan berat badan hewan coba kelinci (O. cuniculus) sebelum dan setelah hiperkolesterolemia dengan pemberian campuran kuning telur ayam ras dan air gula pasir $90 \%$.

Tabel 1. Data Penimbangan Berat Badan Kelinci (O. cuniculus) sebelum dan setelah hiperkolesterolemia (gram)

\begin{tabular}{lll}
\hline Nomor & \multicolumn{2}{l}{ Hasil pengukuran Berat Badan Kelinci $(\mathrm{kg})$} \\
\cline { 2 - 3 } Kelinci & Sebelum hiperkolesterolemia & Setelah hiperkolesterolemia \\
Kelinci 1 & 1,000 & Mati \\
Kelinci 2 & 0,645 & 0,730 \\
Kelinci 3 & 0,560 & Mati \\
Kelinci 4 & 1,370 & 1,430 \\
Kelinci 5 & 1,430 & 1,495 \\
Kelinci 6 & 1,060 & 1,055 \\
\hline
\end{tabular}

Tabel 1 menunjukkan bahwa berat badan kelinci (O. cuniculus) 2, 4 dan 5 mengalami kenaikan.Sedangkan untuk kelinci 6 mengalami penurunan.Dan untuk hewan coba kelinci (O. cuniculus) yang lainnya mengalami kematian. Hasil pemeriksaan kadar kolesterol total hewan coba kelinci (O. cuniculus)sebelum dan setelah hiperkolesterolemia dengan pemberian campuran kuning telur ayam ras dan air gula pasir $90 \%$.

Tabel 2. Data kadar kolesterol total hewan coba kelinci (O. cuniculus) sebelum dan setelah hiperkolesterolemia

\begin{tabular}{lll}
\hline Nomor Kelinci & \multicolumn{2}{c}{ Hasil pengukuran kadar kolesterol (mg/dl) } \\
\cline { 2 - 3 } Kelinci 1 & $\begin{array}{l}\text { Sebelum hiperkolesterolemia } \\
\text { Rendah }\end{array}$ & $\begin{array}{l}\text { Setelah hiperkolesterolemia } \\
\text { Rendah }\end{array}$ \\
Kelinci 2 & Rendah & Tinggi (101) \\
Kelinci 3 & Rendah & Rendah \\
Kelinci 4 & Rendah & Tinggi (127)
\end{tabular}

Tabel 2 Hasil pemeriksaan kadar kolesterol total sebelum hiperkolesterol adalah rendah dan setelah hiperkolesterol adalah kadar tinggi pada 2 ekor kelinci yaitu kelinci nomor 4 adalah $101 \mathrm{mg} / \mathrm{dl}$ dan nomor 6 adalah $127 \mathrm{mg} / \mathrm{dl}$. Dan kadar rendah pada 2 ekor kelinci yaitu nomor 1 dan nomor 3. Sedangkan, 2 ekor kelinci yaitu mengalami kematian saat proses perlakuan hiperkolesterol. Hasil pemeriksaan kadar kolesterol total hewan coba kelinci (O.Cuniculus) sebelum dan setelah pemberian PTU.

Tabel 3. Data kadar kolesterol total hewan coba kelinci (O. cuniculus) sebelum dan setelah pemberian PTU

\begin{tabular}{lll}
\hline Nomor Kelinci & \multicolumn{2}{c}{ Hasil pengukuran kadar kolesterol $(\mathrm{mg} / \mathrm{dl})$} \\
\cline { 2 - 3 } Kelinci 1 & Sebelum pemberian & Setelah pemberian \\
Kelinci 2 & Rendah & Tinggi (100) \\
Kelinci 3 & Tinggi (101) & Tinggi (106) \\
Kelinci 4 & Rendah & Tinggi (110) \\
\hline
\end{tabular}


Tabel 3 menunjukkan bahwa hasil pemeriksaan kadar kolesterol total pada hewan coba kelinci (O. cuniculus) yang masih rendah yaitu no 1 dan 3 mengalami peningkatan dengan pemberian PTU. Hasil pemeriksaan kadar kolesterol total hewan coba kelinci(O. cuniculus) sebelum dan setelah pemberian jus buah PirYali (P. bretschneideri).

Tabel 4. Data kadar kolesterol total hewan coba kelinci (O. cuniculus) sebelum dan setelah pemberian jus buah Pir Yali (P. bretschneideri)

\begin{tabular}{lll}
\hline Nomor & \multicolumn{2}{c}{ Hasil pengukuran kadar kolesterol (mg/dl) } \\
\cline { 2 - 3 } Kelinci & Sebelum pemberian jus buah & Setelah pemberian jus buah Pir \\
& Pir Yali & Yali \\
Kelinci 1 & Tinggi (100) & Rendah \\
Kelinci 2 & Tinggi (106) & Rendah \\
Kelinci 3 & Tinggi (110) & Rendah \\
Kelinci 4 & Tinggi (122) & Rendah \\
\hline
\end{tabular}

Tabel 4 menunjukkan bahwa rerata kadar kolesterol total sebelum pemberian jus buah Pir Yali (P. bretschneideri) adalah Tinggi (lebih dari nilai normal yakni $10-80 \mathrm{mg} / \mathrm{dl}$ ) dan rerata kadar kolesterol total setelah jus buah Pir Yali (P. bretschneideri) adalah rendah (kurang dari nilai normal yakni 10-80mg/dl). Hal tersebut menunjukkan bahwa jus buah Pir Yali (P. bretschneideri) dapat menurunkan kadar kolesterol total pada darah hewan coba kelinci (O. cuniculus).

\section{Pembahasan}

Hewan coba kelinci yang telah diberikan makanan standar ditambah pemberian campuran kuning telur ayam ras dan air gula pasir $90 \%$ selama 7 hari sebanyak 1 x /hari mengalami peningkatan kadar kolesterol total. Rerata kadar kolesterol total pada hewan coba kelinci (O. cuniculus) sebelum hiperkolesterol adalah rendah, sedangkan rerata kadar kolesterol total pada hewan coba kelinci (O. cuniculus) setelah hiperkolesterol adalah tinggi. Hal ini menunjukkan terjadi peningkatan kadar kolesterol total pda hewan coba kelinci (O. cuniculus).

Pemeriksaan kadar kolesterol total dilakukan sebelum dan setelah pemberian jus buah Pir Yali(P. bretschneideri) selama 10 hari. Rerata kadar kolesterol total pada hewan coba kelinci (O. cuniculus) adalah tinggi (lebih dari nilai normal yaitu $10-80 \mathrm{mg} / \mathrm{dl}$ ), sedangkan rerata kadar kolesterol total hewan coba kelinci (O. cuniculus) setelah pemberian jus buah pir yali adalah rendah (kurang dari 10-80mg/dl). Hal ini menunjukkan bahwa pemberian jus buah Pir Yali (P. bretschneideri) berpengaruh atau mampu menurunkan kadar kolesterol total hewan coba kelinci(O. cuniculus).

Hasil penurunan kadar kolesterol total pada penelitian ini secara statistik tidak bisa ditentukan karena nilai hasil pengukuran tidak menunjukkan hasil pada kadar rendah, sehingga hasil penelitian dijelaskan secara deskriptif. Penurunan kadar koleserol total dapat disebabkan oleh kandungan serat dan vitamin $\mathrm{C}$ (Asam askorbat) pada buah Pir Yali(P. bretschneideri). Serat dapat menunda pengosogan lambung sehingga rasa kenyang menjadi lebih lama akibatnya asupan kalori menjadi berkurang. Pada saat seperti ini sekresi insulin akan berkurang dan diikuti dengan penghambatan kerja enzim HMG-KoA reduktase sehingga sintesis kolesterol menurun. Kerja enzim ini distimulasi oleh adanya insulin dan tiroksin tetapi dihambat oleh adanya glucagon.

Sianturi (2002) menyatakan bahwa vitamin C (Asam askorbat) menurunkan kadar kolesterol total dan trigliserida pada orang yang mempunyai kadar tinggi tetapi tidak pada mereka yang berkadar normal. Ini berarti vitamin $\mathrm{C}$ (Asam askorbat)berperan sebagai homeostatis untuk mencapai keseimbangan. Konsumsi Vitamin C (Asam askorbat) 1 gram sehari setelah 3 bulan akan menurunkan kolesterol 10\% dan trigliserida 40\%. Kandungan vitamin B3 (niacin) juga dapat menurunkan produksi VLDL, sehingga kadar IDL dan LDL menurun yang akan berdampak pada menurunnya kadar kolesterol 8 total serum. Kandungan kolesterol total dalam tubuh manusia itu sangat penting, namun jika jumlah kadar kolesterol total meningkat dari nilai normalnya makan akan berbahaya bagi tubuh manusia dimana akan menyebabkan hiperkolesterolemia yang akan menyebabkan anteroklerosis. 


\section{Kesimpulan}

Ada pengaruh yang bermakna pada pemberian jus buah Pir Yali (P. bretschneideri) terhadap kadar kolesterol total pada hewan coba kelinci (O. cuniculus). Saran bagi peneliti selanjutnya sebaiknya menggunakan ekstrak buah Pir Yali (P. bretschneideri) agar didapatkan hasil penurunan kadar kolesterol yang lebih tinggi

\section{Referensi}

Adiyanto, I.O. 2009. Pengaruh Lama Perendaman Gigi Dengan Jus Buah (Pyrus communis) Terhadap Perubahan Warna Gigi Pada Proses Pemutihan Gigi Secara In Vitro. Skripsi.Fakultas Kedokteran Universitas Diponegoro. Semarang

Aglabunny, 2018. Data Biologis Kelinci. Di dalam https://aglabunny.wordpress.com/about/about-rabbit/databiologis-kelinci/

Andygian, V. 2013. Pengaruh Pemberian Jus Kulit Delima (Punica Granatum) Terhadap Kadar Kolesterol Total Wanita Hiperkolesterolemia.Skripsi. Semarang: Universitas Diponogoro

Champe, dkk. 2004. Biokimia ulasan bergambar. Buku Kedokteran EGC. Jakarta

Erni dkk.2014. Pengaruh Pemberian Minyak Mandar Yang Ditambahkan Bubuk Daun Sukun (Arthocarpus Altilis) Terhadap Kadar Kolesterol Mencit (Mus Musculus).Jurnal Bionature, 15 (2)

Glory dkk. 2016. Perubahan kadar kolesterol total dan trigliserida pada kelinci NewZealandwhite yang diberi ekstrak beras hitam (Oriza sativa L.). Jurnal e-Biomedik (eBm), 4(1)

Goodman, S. 2002. Ester C Vitamin Generasi III.Gramedia Pustaka Utama, Jakarta.

Hakimah, I. A,. 2010. 81 Macam Buah Berkhasiat Istimewa. Syura Media Utama. Jawa Tengah.

HarmitadanRadjiM,2008.Buku Ajar Analisis Hayati.PenerbitEGC

Islamiyah, 2010. Pengaruh Pemberian Ekstrak Buah Jambu Biji (Psidium Guajava.L) Terhadap Kadar Kolesterol Total, Hdl,Ldl, Dan Trigliserida Darah Tikus Putih (Rattus Norvegicus) Yang Diinduksi Aloksan. Skripsi. Universitas Islam Negri (Uin) Maulana Malik Ibrahim: Malang

Lailiya, 2011. Pengaruh Pemberian Jus Apel Terhadap Penurunan Kadar Kolesterol pada Usia Lanjut di PSTW Unit Budhi Luhur Kasongan Bangunjiwo Kasihan Bantul Yogyakarta. Naskah Pustaka

Mamat. 2010. Faktor-Faktor Yang Berhubungan Dengan Kadar Kolesterol HDL di Indonesia. FKUI

Marks, dkk.1996.Biokimia Kedokteran Dasar. Buku Kedokteran EGC.Jakarta

Murray, dkk. 2006. Biokimia Harper. Penerbit Buku Kedokteran EGC. Jakarta

Notoadmodjo, 2005. Metodologi Penelitian Kesehatan. Jakarta : Rineka Cipta

Rimba, Z. 2011. Gambaran Kadar Kolesterol Total Pada Penderita Diabetes Melitus Tipe 2 Di Rsupn Cipto Mangunkusumo Tahun 2010. Skripsi. Fakultas Kedokteran Program Studi Kedokteran Umum : Jakarta

Sari dkk. 2010. Faktor Resiko Kolesterol Total Pasien Penyakit Jantung Koroner Dirumah Sakit Achmad Mochtar Bukit Tinggi. Jurnal Kesehatan Masyarakat, 4 (2)

Silva, G. J., Tatiane Medeiros Souza, Rosa Lía Barbieri, and Antonio Costa de Oliveira.2014. Origin, Domestication, and Dispersing of Pear(Pyrus spp.). Advances in Agriculture. Federal University of Pelotas,RS, Brazil P 8.

Soelistijani, DA. 2002. Sehat dengan Menu Berserat. Jakarta : Trubus Agriwidya. 
Sudoyo, A. W., Setiyohadi, B., Alwi, I., K Simadibrata, M., dan Setiati, S., 2006. Ilmu Penyakit Dalam, Pusat Penerbitan Departemen Ilmu Penyakit Dalam. Fakultas Kedokteran Universitas Indonesia, Jakarta.

Sulistyaningsih dan Mulyati. 2015. Pengaruh Pemberian Ekstrak Kacang Hijau Terhadap Kadar Kolestrol Total Pada Wanita Hiperkolesterolemia. Journal of Nutrition College, 4 (2).

Vanessa, R., Lorensia M. E. P., \& Yuniarti A. (2013). Pemanfaatan minuman serbuk instan kayu manis (Cinnamomun burmaniiBI.) Untuk menurunkan kadar kolesterol total darah pada tikus putih (Rattus norvegicus). Jurnal dari Jurusan Teknobiologi Universitas Atma Jaya Yogyakarta, 1(1): 1-14.

Veterinaria, J. M., Klinik, L., Kedokteran, F., Universitas, H., Kuala, S., \& Aceh, B. (2014). Pengaruh Pemberian Jus Nanas (A Nanas Comosus) Terhadap Kadar Kolesterol Total Darah Kelinci (Oryotolagus Cuniculus) Hiperkolesterolemia The Effect Of Pineaple Juice (Ananas Comosus) On Blood Cholesterol Level Of Rabbit, 8(1), 2-4.

Widodo. 2017. Usaha Budidaya Ternak Kelinci Dan Potensinya. Magelang: Kelompok Peternak Kelinci Mandiri.

Zaki dkk. 2015. Pengaruh Pemberian Jus Mangga Terhadap Profil Lipid Dan Malondialdehyde Pada Tikus Yang Diberi Minyak Jelantah. Jurnal Gizi Indonesia, 3 (2).

Zuhrawati, N. 2014. Pengaruh Pemberian Jus Nanas (Ananas Comosus) Terhadap Kadar Kolesterol Total Darah Kelinci (Oryotolagus Cuniculus) Hiperkolesterolemia. Jurnal MedikaVeterinaria, 8 (1). 